\section{AGENCIAMENTO E ANÁLISE DE DOMÍNIO: um encontro possível}

Igor Soares Amorim*

Lígia Maria Cafét

RESUMO: $\quad$ Com base na constatação da forte presença da Análise do Domínio $(A D)$ como orientação teórica e/ou metodológica das investigações no campo da Organização do Conhecimento, apresenta-se esta pesquisa que visa aprofundar o entendimento sobre o conceito de $A D$, adotando para tal o olhar da Filosofia de Deleuze e Guattari. O estudo se configura como uma investigação qualitativa, exploratória e bibliográfica que adota como técnica a Análise de Conteúdo. O corpus se constitui de 42 artigos de autoria de Hjørland (em parceria ou não) publicados entre os anos de 1990 e 2014, recuperados na Library and Information Science Abstracts (LISA), Web of Science (WoS) e Scopus. A variável de análise foi identificada na obra Mil Platôs de Deleuze e Guattari. A leitura flutuante dos textos selecionados possibilitou detectar três conceitos principais da $A D$ (comunidade discursiva, domínio e linguagem). Com base nos contextos de ocorrência destes conceitos foram formuladas "definições" para cada um deles. Estas "definições" foram reinterpretadas à luz da variável de inferência "agenciamento", o que resultou em uma re-apresentação do significado de AD. O tratamento dos dados revela a coerência da $A D$ nos limites daquilo que lhe é conferido e oferece um quadro norteador para aqueles que almejem aplicar teórica ou metodologicamente a $A D$ em seus estudos.

Palavras-chave Análise de Domínio. Agenciamento. Organização do Conhecimento. Filosofia. Ciência.

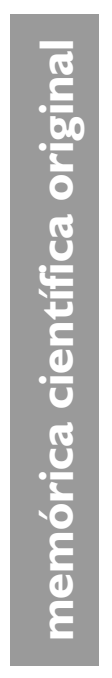

\footnotetext{
* Mestre em Ciência da Informação pela Universidade Federal de Santa Catarina, Brasil. Doutorando em Ciência da Informação no Programa de Pós-Graduação em Ciência da Informação da Universidade Federal de Santa Catarina, Brasil. Pesquisador da Universidade Federal de Santa Catarina, Brasil. E-mail: igao.sa@gmail.com.

** Doutora em Lingüística pela Université Laval, Canadá. Professora Associada da Universidade Federal de Santa Catarina, Brasil. Docente permanente no Programa de Pós-Graduação em Ciência da Informação da Universidade Federal de santa Catarina, Brasil.

E-mail: ligia.cafe@ufsc.br.
}

\section{INTRODUÇÃO}

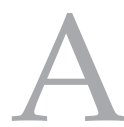

Análise de Domínio - AD é uma abordagem teórica e metodológica, pois afirma a base sociocultural das ações de informação na mesma medida que objetiva direcionar o mapeamento de um dado cenário informacional. Desde que foi proposta na Biblioteconomia e Ciência da Informação BCI na década de 1990, a AD é envolta de certa controvérsia: "Is domain-analysis really new? Or is it old wine in new bottles?" (HJØRLAND; AIBRECHTSEN, 1995, p. 400). Essas dúvidas direcionam a atenção às etapas metodológicas da proposta hjørlandiana. Nesse contexto, Tennis (2003) propõe procedimentos para a AD, os quais foram rebatidos por Hjørland (2013) que os considerou limitantes e rígidos frente multiplicidades de domínios possíveis de serem analisados. Percebemos o esforço de Hjørland (2013) em preservar a flexibilidade metodológica da AD a fim de garantir sua ampla aplicabilidade, e o respeito às diferenças específicas expressas por cada domínio.

Nesta encruzilhada, sustentamos que uma abordagem teórica que considere a 
multiplicidade, que seja flexível e consistente pode revelar novas perspectivas sobre a $\mathrm{AD}$, de modo que a dialética teoria-prática seja complementar, e não conflitante, tal como vem se demonstrando. Tomando como subsídio a Filosofia de Deleuze e Guattari, problematizamos: De que modo a Filosofia de Deleuze e Guattari pode colaborar com uma proposta mais plural da AD? Assim, objetivamos propor elementos para uma base teórico-metodológica que sirva ao reconhecimento de uma diversidade de domínios, evitando o engessamento derivado das perspectivas cientificistas.

De forma a contribuir para o avanço do entendimento da $\mathrm{AD}$, apresentamos neste artigo uma reflexão acerca de três principais conceitos presentes na AD: "comunidade discursiva", "domínio" e "linguagem". Como fio condutor desta reflexão aplicamos o conceito de "agenciamento", trabalhado no livro Mil Platôs, de Deleuze e Guattari (2011a, 2011b, 2012a, 2012b, 2012c), uma das obras "mais radicalmente consistente, do ponto de vista conceitual, e mais consistentemente radical, do ponto de vista político, produzida na Filosofia da segunda metade do século XX" (CASTRO, 2007, p. 92).

É importante ressaltar que a perspectiva de Deleuze e Guattari (2010) é uma alternativa às Filosofias frutificadas na virada linguística. Todavia, ainda assim, os franceses desenvolvem uma abordagem pragmática, na medida em que se debruçam sobre a materialidade dos fluxos, das relações, das ações de poder e resistência, dos afetos. Nesse sentido, a Filosofia de Deleuze e Guattari (2010) é além da linguagem, não a considerando como essencial nas relações do ser com o mundo, mas apenas um dos elementos que participa do agenciamento entre os polos virtual e atual. É uma Filosofia dos fluxos que pode corroborar com uma nova apreensão da informação e das práticas informacionais no seio da BCI. Nesse sentido, Castro (2007) argumenta que nesse começo de século as Ciências Humanas principiam uma nova virada, numa direção distinta da virada linguística do século $X X$, para outro macroparadigma.

Castro (2007, p. 94) lança uma frase paradoxal sobre uma possível sensação resultante da leitura de algumas obras de Deleuze e Guattari, uma sensação de "déjà vu as avessas: já vi isso escrito depois [...]". Tal estranheza seria o reconhecimento dessa nova virada nas Ciências
Humanas, na qual tentamos lançar a AD a fim de ratificar sua consistência e flexibilidade teórica, assim como para esclarecer sua aplicabilidade.

\section{CIÊNCIA E FILOSOFIA: considerações sobre a análise de domínio e o conceito de agenciamento}

Para Deleuze e Guattari (2010), Filosofia e Ciência são formas absolutas de criação, que trazem o novo do virtual ao atual a partir do traçar de um plano sobre o Caos. Segundo os filósofos franceses, o Caos contém todas as "partículas possíveis e suscitando todas as formas possíveis que surgem para desacelerar logo em seguida, sem consistência nem referência, sem consequência" (DELEUZE; GUATTARI, 2010, p. 140).

Assim, quando averiguamos as inovações conceituais ou as referenciaisdiscursivas na Filosofia ou na Ciência, estamos diante de um movimento que ocorre não só nas estruturas mentais que posteriormente são traduzidas num livro ou artigo. Há um fluxo intensivo, pré-subjetivo, pré-social, que perpassa toda e qualquer novidade. Nesse entendimento, uma empreitada científica na OC ou na BCI que almeje inovar, necessita mergulhar nesse fluxo de intensidades, como ensinam os pensadores franceses.

Basicamente, são três elementos que operam na criação: 1) um plano de imanência que se estende sobre o Caos intensivo, 2) a resultante da criação (conceito na Filosofia e a função na Ciência), e 3) um agente que flutua entre o plano e a resultante. O plano é o que torna o Caos acessível, visto que nele a única ordem possível é a da velocidade infinita, o plano é um recorte, um crivo no Caos, é o que nos permite pensá-lo, ou seja, é a chave para a criação.

O plano na Filosofia, chamado de planômeno, serve de base para os conceitos. O filósofo é um criador de conceito. Como relata Berti (2012), para os pensadores franceses os conceitos não são apenas enunciados, visto que operam singularidades (intensivas). Um conceito, diferentemente da sensação que constrói uma figura, procura captar a dinâmica das intensidades. Denominado de personagem conceitual, o agente da Filosofia faz o trânsito 
de intensidades selecionadas no plano que vão encorpando o conceito.

A Ciência também traça um plano no Caos. O plano de referência desenvolve as bases para a construção das funções. Por meio de seus agentes, os observadores parciais, a Ciência adentra ao Caos, seleciona intensidades e as desaceleram, tornando-as variáveis. As variáveis são postas sobre um eixo de equilíbrio, garantindo assim a possibilidade de referência. Nesse sentido, a Ciência não cessa de atualizar, por funções, o acontecimento num estado de coisas, numa coisa ou num corpo referível.

Na Filosofia, o conceito é o ponto de condensação dos componentes retirados do Caos. Nesse sentido, Deleuze e Guattari (2010) afirmam que os conceitos têm história e devir, o que se entende como modos de conexão interconceitual que ocorrem por meio de vibrações, os conceitos vibram. Já a função só é possível mediante um sistema de referência, isto é, ela depende da desaceleração das intensidades captadas no Caos sobre o plano de referência, e quando são estabilizadas em eixos e coordenadas, são denominadas de functivos. Toda função científica tem por base um conjunto relacionado de functivos.

Conforme são acrescidas novas variáveis aos sistemas de referência, o plano de referência adquire novas dimensões. Esse plano sustenta estudos sobre estados de coisa (isto é, estudos matemáticos, valores característicos de algum objeto), coisa em si (isto é, estudos como os da Física, que tomam como objeto determinadas forças), corpos (isto é, estudos que buscam o entendimento dos organismos) (DELEUZE; GUATTARI, 2010). Ainda, há outra modalidade científica, que incorpora elementos discursivos em suas formulações, e dependem não apenas dos functivos, mas também dos prospectos, que são fundamentos das proposições (BROWN, 2009; DELEUZE; GUATTARI, 2010).

Partindo dessa imagem de Filosofia e Ciência, esta pesquisa optou por um conceito dentre os vários criados por Deleuze e Guattari, o conceito de agenciamento; enquanto em Hjørland, optamos pelas noções de comunidade discursiva, domínio e linguagem, compreendidos como elementos discursivos compostos por prospectos. As duas subseções seguintes adentram ao conceito de agenciamento e as noções hjørlandianas em questão.

\section{I Hjørland e análise de domínio: um produto, uma proposta}

A AD apresenta-se atualmente como uma das mais importantes teorias tanto na Organização do Conhecimento - OC como na BCI. Tal condição fez de Hjørland um dos autores mais citados na OC (SMIRAGLIA, 2014).

A proposta é pragmática e seu intuito é garantir uma vertente de base sociocultural em detrimento das tradições mais positivista, que operam pela abordagem cognitivista da informação.

A perspectiva suscita claras conexões com a produção intelectual de Wittigeinsttein, Vigotsky e Dewey, ao passo que confere destaque ao uso situacional dos documentos, quer dizer, a informação documentária deve ser entendida como uma ação, vinculada à um contexto específico, às instituições $\mathrm{e}$ às ferramentas empregadas.

Hjørland põe em diálogo sua produção com diversas noções consolidadas na Filosofia e nas Ciências Sociais e Humanidades; citamos as noções de "jogos de linguagem", de "mediação", de "divisão social do trabalho", que são atualizadas nas proposições do bibliotecário dinamarquês. Em Dewey, Hjørland vai buscar essa perspectiva de "divisão social do trabalho" (BOMENY, 2005), como prospecto que garante a homogeneidade das comunidades, de pequenos grupos que participam de processos informativos e que se estruturam em função dessa noção deweyana. A "mediação" em Vigotsky permite a Hjørland compreender as interações sociais (que, além dos sujeitos, envolvem instrumentos e signos) como produtivas (MARTINS; MOSER, 2012), as quais, na $A D$, implicam na consolidação da própria informação. Ainda, a noção de "jogos de linguagem" wittgensteiniana subsidia a questão das comunidades discursivas, fundamentais no estabelecimento dos significados aos conceitos (WESOLEK, 2012).

[...] a análise de domínio é especialmente importante para a pesquisa em organização do conhecimento, notadamente no que se refere a estudos sobre a configuração epistemológica da área, os processos sociais que permeiam a construção da área (p.ex. produção e comunicação científica) e, ainda, para - desenvolvimento de sistemas de 
organização do conhecimento (como as linguagens de indexação, por exemplo), pois tal aspecto propiciará cada vez mais uma abordagem contextual, em consonância com os valores inerentes ao seus processos de produção e de uso, sem desconsiderar, ainda, os elementos idiossincráticos que permeiam todo o processo de organização em si mesmo. (GUIMARÃES, 2014, p. I9)

Nesse sentido, a AD hjørlandiana se cristaliza como conjunto de discursos científicos, que encadeia palavras de ordem constituídas em proposições que, por sua vez, garantem sua validade segundo alguns critérios. É assim que se constitui o produto de Hjørland, a AD.

Hjørland não define rigorosamente os métodos, apenas indica algumas direções para a aplicação da $\mathrm{AD}$, a qual se daria por meio de três pilares: um epistemológico, um ontológico e outro sociológico (HJØRLAND; HARTEL, 2003). Segundo Hjørland e Hartel (2003), a dimensão epistemológica é de grande importância, pois há um movimento de descendência que faz desse espaço condicionante das outras duas dimensões, na medida em que influi na estabilização da "relevância", dos "sistemas de classificação", dos "gêneros" e dos "documentos" de um determinado domínio. A dimensão ontológica busca reconhecer o conteúdo produzido no domínio, assim, é um vetor que pode esclarecer questões relacionadas com os seguintes tópicos: área, domínio, elementos, campos, objetos, problemas, assuntos, entre outros. Por fim, a dimensão sociológica permite a verificação das estruturas de poder no domínio, isto é, as estruturas definidas na comunidade discursiva, e sua consequente utilização valorativa dos conceitos do domínio (HJØRLAND; HARTEL, 2003).

Noutro momento, Hjørland ratifica a proximidade da sua proposta com a abordagem epistemológica, esclarecendo que, para realizar a $\mathrm{AD}$, é necessário mapear em qual corrente epistemológica os enunciados do domínio se enquadram. Hjørland (1998) desenvolve quatro categorias (analíticas) que, na aplicação da AD, servem para caracterizar os enunciados dos domínios segundo seu viés epistemológico: a corrente empirista; a racionalista; o historicismo e o pragmatismo. Hjørland não explora os termos em seus aspectos filosóficos, conferindo uma abordagem não tão aprofundada. Todavia, o objetivo do dinamarquês é antes definir categorias analíticas, que discorrer criticamente sobre tais correntes (HJØRLAND, 1998).

Com isso, notamos a busca de Hjørland por algumas ações de aplicação da $\mathrm{AD}$ pelo estabelecimento do que chamamos de categorias analíticas. Todavia, ainda assim, sua proposta é questionada a ponto de não garantir um entendimento compartilhado dela na área, o que é ratificado pela proposta de Tennis (2003).

\subsection{Conceito filosófico: a noção de agenciamento}

Se por um lado, Deleuze e Guattari (2010) afirmam a discrepância entre Filosofia e Ciência, cada uma com seu plano e sua forma exclusiva de criação, os autores destacam as possibilidades de deslizamentos entre os planos. Isso significa que um conceito filosófico pode deslizar do planômeno para um plano de referência, adquirir uma consistência referencial e discursiva a fim de dizer sobre estados de coisa, coisas ou corpos. Do mesmo modo, um functivo ou prospecto pode ser deslocado ao plano filosófico, e incentivar novos conceitos. Intencionamos o deslizamento do conceito de agenciamento ao plano de referência da BCI.

O conceito de agenciamento de Deleuze e Guattari servirá como epicentro para repensarmos a AD. Pretendemos deslocá-lo ao plano de referência, com o intuito de repensar aspectos teóricos e metodológicos da teoria hjørlandiana.

Deleuze e Guattari não apresentam uma definição exata do conceito de agenciamento, eles se preocupam antes com seu funcionamento. Sua função é articular elementos na passagem de duplo sentido estabelecida entre o Caos e as estratificações (o conceito ou a função/ preposição), ou seja, diz respeito aos movimentos virtualização-atualização. Deleuze e Parnet (1998, p. 43) ensinam que o agenciamento é uma simbiose, um cofuncionamento, isto é, o esforço entre os corpos, sendo que os corpos podem ser "físicos, biológicos, psíquicos, sociais, verbais". Por isso, agenciar é estar no meio, entre os corpos, de forma que todo e qualquer agenciamento se dá entre diversos outros agenciamentos. Não há relações de "sujeito-objeto", pois o agenciamento 
é uma "simpatia", sempre constituída por alianças que formam complexos de relações. É por meio de um agenciamento que estratos são produzidos, sobre os quais intensidades heterogêneas são estabilizadas.

Deleuze (1988) explica, há quatro dimensões num agenciamento: estado de coisas ou corpos, as enunciações, territórios e os movimentos de desterritorialização. Os estados de coisas ou corpos se revelam nos encontros, que podem ser de composição ou de decomposição. Os enunciados são estilos, isto é, um modo de falar, de escrever, de andar, de um dado lugar etc; são estilos de enunciação. Ainda, um agenciamento sempre implica em territórios, "onde nos sentimos melhor", mas há também em processos de desterritorialização, o modo como saímos do território. Esses quatros componentes fundamentam o conceito de agenciamento deleuzo-guattariano.

Além disso, Deleuze e Guattari (2011a, 2011b, 2012a, 2012b, 2012c) afirmam que o agenciamento coopera com o processo de diferenciação em âmbito químico, orgânico e antropomórfico, colocando em conjunção os heterogêneos e possibilitando os movimentos de atualização e de virtualização.

Para realizar a transição das intensidades aos corpos molares, é necessária uma dupla articulação. A primeira se refere ao aprisionamento ou fixação das intensidades, o qual se opera pela seleção e a ordenação estática de ligação e sucessão nas unidades moleculares. A segunda articulação diz respeito à constituição dos elementos molares, a qual se dá pela instauração de estruturas estáveis que se atualizam nos compostos molares que derivam das próprias estruturas. (DELEUZE, GUATTARI, 2011a).

Não nos interessa aqui especificar os procedimentos gerativos dos estratos químicos e orgânicos, mas sim o antropomórfico, o qual traz à tona os aspectos sociais e de linguagem. Sobre isto, Deleuze e Guattari retomam os estudos de Hjelmslev sobre linguagem, lembrando-se dos conceitos de matéria, expressão e conteúdo. A noção de matéria indica uma condição intensiva inicial, conteúdo remete aos corpos e as matérias dos corpos (estado de coisas), já a expressão remete aos enunciados. Conteúdo e expressão, assim, apresentam-se vinculados, porém são independentes, assim constituem a dupla articulação, assim são responsáveis pela distribuição das estruturas moleculares e molares, chegando à composição de um estrato ou território.

A dupla articulação revela a dinâmica que ocorre entre o virtual e o atual, entre o molecular e o molar. É um fluxo incessante, que se estabelece entre uma molaridade e um meio associado, um fluxo tão vivo que dilui os contornos possíveis, tornando centro e periferia uma única manifestação. $\mathrm{O}$ meio associado troca com a molaridade elementos, do mesmo modo que recebe outros elementos da mesma. $O$ que conecta a molaridade e o meio são infinitas camadas, mil platôs, que extingue as noções "dentro" e "fora". Há sempre um "fora" associado, fornecendo e recebendo elementos, transformando a molaridade, isto, provocando movimentos de desterritorializações (abdicar do que se era) e reterritorializações (compor-se com a diferença) (DELEUZE; GUATTARI, 2011a).

No estrato antropomórfico, a dupla "conteúdo e expressão" tornam-se mais independentes que nos outros estratos, assim passam a sofrerem modificações específicas. A expressão devém linguística, enquanto que o conteúdo devém atividade. Nesse estrato, há nova distribuição do conteúdo e da expressão. Nesse sentido, conteúdo pode devir uma mão ou uma ferramenta, assim como a expressão devir substância vocal. A substância vocal existe segundo uma síntese formal da sucessão no tempo, de forma a codificar-se linearmente, um som por vez. É um processo que os filósofos chamam de tradução, o qual possibilita a linguagem falar sobre si e outros estratos. Os filósofos revelam que, dessa forma, anterior a atividade ou a linguagem, há máquinas condicionando o aparecimento destas, máquinas que dizem respeito à formação de potência e agentes que atuam "tanto na constituição das línguas, das ferramentas, quanto para seus usos, suas comunicações e difusões mútuas ou respectivas" (DELEUZE; GUATTARI, 2011a, p. 101). O conteúdo-tecnológico evoca uma máquina social técnica, a expressão-semiótica, uma máquina coletiva semiótica.

Nesse cenário, os pensadores franceses alertam para um perigo relativo à imposição do significante sobre a diversidade do signo. Segundo os autores, a tradição linguista favoreceu um despotismo do significante, ao reduzir 
a dimensão do conteúdo ao significado e da expressão ao significante. Assim, é questionada a decomposição do significante a partir da palavra e a do significado a parir da coisa. Não há uma palavra específica para qual uma forma de conteúdo remeteria, senão um conjunto de enunciados constituídos num dado campo social. Desta forma, são duas multiplicidades independentes, uma discursiva (de expressão) e outra não-discursiva (de conteúdo), mas que não param de se implicarem: "Em suma, não se deve jamais confrontar palavras e coisas supostamente correspondentes, nem significantes e significados supostamente conformes, mas sim formalizações distintas em estado de equilíbrio instável ou pressuposição recíproca." (DELEUZE; GUATTARI, 2011a, p. 107).

Além dos corpos e das enunciações, um agenciamento é composto pelos movimentos de territorialização, desterritorialização e reterritorialização. Esses movimentos fixam os agenciamentos, os estados de coisa e os enunciados no plano de consistência, no plano de organização ou nos seus entremeios. A reterritorialização trata de uma (nova) distribuição da terra, conferindo substância ao conteúdo (corpos) e código à enunciação (expressão); mas que não ocorre sem uma desterritorialização, a qual liberta a matéria, arrastando o conteúdo e a expressão sobre uma linha de fuga, uma linha de devir. Nesses dois movimentos, são constituídos blocos de devir, implicando sempre outro-da-relação entre os componentes do agenciamento, deste modo nada se conserva em si nessa malha de transformação. São os devires ou as linhas de fuga que produzem o novo. (DELEUZE; PARNET, 1998).

Um território é como um estrato. Tem meio associado, do qual seleciona, elimina e extraem elementos que o confere forças terrestres para não submergir. Todo território é um ato: territorialização. É também expressivo, por carregar marcas, assinaturas que o delimita, impondo-lhe uma distância do Caos, das virtualidades, permitindo-lhe assegurar as diferenças específicas e as identidades. Porém, o movimento de territorializar sempre ocorre em conjunto com a desterritorialização. Esse segundo movimento ocorre quando o meio associado atravessa o território.

Um território é composto por suas marcas, cores, odores, sons, posturas, materiais, etc. Em sua movimentação dupla, a consistência territorial é garantida pela coexistência de seus compostos. A coexistência depende do acumulo de riqueza que o território adquire ao passar pela dupla articulação. A desterritorialização é operada de forma maquínica, de modo a efetuar aberturas a outros agenciamentos ou fechamentos em si mesmo.

"O agenciamento territorial implica uma descodificação, e ele próprio não é separável de uma desterritorialização que o afeta" (DELEUZE; GUATTARI, 2012b, p. 158-159). O agenciamento desterritorializado põe em relação os heterogêneos, sem hierarquia ou ordem, tendo sua consistência garantida pelas transversais. Transversal é um componente que assume o vetor de desterritorialização mantendo junto todos os componentes. É a transversal que mantém o agenciamento desterritorializado, impedindo-o dele se dissolver no fluxo das intensidades. Desta maneira, há oposição entre a consistência dos agenciamentos e a estratificação dos meios. Os meios oscilam entre a reterritorialização e a abertura desterritorializante que os conecta com o plano de consistência. Então, é importante ressaltar que é no plano de consistência que os estratos endurecem e se organizam, e que é nos estratos que o plano de consistência trabalha e se constrói (DELEUZE; GUATTARI, 2012b, p. 160).

\section{PROCEDIMENTOS METODOLÓGICOS}

Esta investigação caracteriza-se como qualitativa, exploratória e bibliográfica. O corpus da pesquisa foi coletado nas seguintes fontes: artigos de autoria de Hjørland (em parceria ou não) entre os anos de 1990 e 2014, recuperados na Library and Information Science Abstracts (LISA), Web of Science (WoS), e Scopus. A obra Mil Platôs de Deleuze e Guattari foi eleita para selecionar a variável de análise dos dados extraídos das fontes. Delimitamos os artigos de Hjørland no período citado, pois é neste que foi concebida a AD. O livro dos filósofos foi selecionado devido a sua representatividade na obra geral de seus autores, além de abordar de forma mais concreta o conceito de agenciamento.

Utilizamos como método de pesquisa a Análise de Conteúdo de Bardin (2003), uma metodologia que abrange de forma sistemática o tratamento e análise dos dados, compreendendo 
etapas que vão desde o levantamento e seleção de bibliografias e estruturação do corpus de análise, até a etapa de tratamento de resultados, construção de inferências e interpretação. Bardin (2003) relata que a Análise de Conteúdo é composta por três fases: a pré-análise, a exploração do material e o tratamento dos resultados, inferências e interpretações.

$\mathrm{Na}$ pré-análise, selecionamos as bibliografias, definimos o corpus de pesquisa e estabelecemos a posteriore três índices de análise que foram explorados nos artigos de autoria de Hjørland por meio da leitura flutuante: "comunidade discursiva", "domínio" e "linguagem". O estabelecimento desses índices se deu indutivamente, no próprio processo de leitura da bibliografia, seguindo as indicações de Bardin (2003). Esse processamento sobre a bibliografia foi adotado também para a definição do corpus relativo à Filosofia deleuzo-guattariana e o estabelecimento da variável de análise, o conceito de "agenciamento".

$\mathrm{Na}$ etapa de exploração do material e tratamento dos resultados, tomamos os termos "comunidade discursiva", "domínio" e "linguagem" como unidade de registro, e o parágrafo em que ocorriam, como unidade de contexto. Cada unidade de contexto foi extraída de seu respectivo texto e inserida numa ficha documental. A reunião dessas unidades de contexto subsidiou um primeiro movimento interpretativo, de estabilização sintética das significações de tais termos empregados por Hjørland - isto, já na terceira etapa da Análise de Conteúdo. Com relação ao conceito de "agenciamento", o elegemos por ser um conceito que representa o processo de associação entre diferentes entes no processo de atualizaçãovirtualização, ou seja, é um conceito que confere liga a um grupo, a um domínio. Tal conceito, na Análise de Conteúdo, participou como polo de atração responsável por orientar as inferências, sendo o motivo ou as lentes da análise. As inferências e interpretações emergiam conforme tratávamos os dados em nossas fichas e quadros.

Utilizamos duas diferentes fichas documentais, a primeira serviu para extração dos índices junto a sua unidade de contexto (o parágrafo em que o termo ocorria) e trazia uma última linha relativa à consolidação de uma definição para cada termo. Usamos uma ficha para cada texto de Hjørland. Após a consolidação das definições de cada índice por artigo, elas foram reunidas numa segunda ficha, com a intenção de delimitar uma definição geral para cada índice.

Com base nessas definições gerais, constituímos um quadro (quadro 1) de cruzamento, visando confrontar as definições dos índices com a variável "agenciamento" reconhecida no livro Mil Platôs de Deleuze e Guattari (2011a, 2011b, 2012a, 2012b, 2012c).

\section{RESULTADOS E DISCUSSÕES}

Depois da filtragem dos artigos recuperados, obtivemos o número de 42 artigos de autoria de Hjørland, a partir dos quais estabelecemos os índices. Esses índices foram cruzados com a variável "agenciamento", a qual ocorre ao longo de todos os capítulos dos cinco volumes de Mil Platôs.

Com a intenção de delimitarmos um pouco mais os aspectos conceituais da $\mathrm{AD}$, realizamos a aplicação da Análise de Conteúdo a partir de termos eleitos como fundamentos dessa teoria, "comunidade discursiva", "domínio" e "linguagem". Destacamos que Hjørland trabalha com certa flexibilidade conceitual, isto é, não se preocupa em diferenciar e/ou hierarquizar os conceitos fundamentais de seus textos, permitindo uma ampla intersecção semântica entre esses.

O termo "comunidade discursiva" às vezes aparece como sinônimo de disciplina, ou, quando às vezes perde espaço para o uso de termos concorrentes, surge como "comunidade científica", "comunidade epistêmica" ou "comunidade de usuários". No final de nossa análise de conteúdo, foi possível identificar as principais propriedades desse termo. Desse modo, delimitamos "comunidade discursiva" como: uma organização social que ordena e limita o processo comunicacional num domínio, constituindo como o epicentro de interesse da Análise de Domínio. Composta por atores (produtores, intermediários e usuários dos documentos), instituições e serviços de informação, que se arranjam segundo uma divisão social do trabalho. A comunidade discursiva é responsável pelo estabelecimento da estrutura de informação na medida em que moldam as ferramentas, as linguagens, os conceitos, os significados, as necessidades e os critérios de relevância informacional.

Com relação ao termo "domínio", o caracterizamos como: condicionante da produção 
de conhecimento, assim como já constitui em si um conjunto de conhecimento. Pode ser delimitado por um grupo de usuários, uma disciplina, uma empresa ou um amplo campo de conhecimento, dotados de necessidades informacionais e constituídos por paradigmas, tradições e escolas que definem suas teorias. Apresenta padrões nas práticas de comunicação. É uma entidade dinâmica que carrega a heterogeneidade de vozes, mas que também é afetado por externalidades, como as tecnologias, os recursos financeiros e o grau de objetividade das pesquisas; por isso é fundamentalmente constituído nas dinâmicas socioculturais.

Por fim, a noção do termo "linguagem" foi entendida como: uma instituição sociocultural e produtora de significados. É na linguagem que valores funcionais são atribuídos aos signos, o que culmina com os atos de comunicação, por isso é caracterizada por/nas situações específicas (jogos de linguagem). Permite a socialização dos atores e a pode revela a matriz teórica que caracteriza um conjunto de documentos e de atores que envolvem $e$ processam os documentos. Interfere na percepção que pessoas têm dos objetos, na media em que participa do processamento e armazenamento de informações mentais que as pessoas fazem em seu dia-a-dia.

Reforçamos que Hjørland não se propõe a definir tais termos em seus artigos, sendo que realizamos apenas uma síntese consolidada de suas principais ideias a respeito de cada índice a fim de entender como eles são explorados na $\mathrm{AD}$ pelo dinamarquês. Além disso, a consolidação desses índices nos servirá para a reinterpretação da AD sob a luz da Filosofia deleuzo-guattariana.

Com relação a variável "agenciamento", buscamos no pensamento de Deleuze e Guattari elementos que nos possibilitassem entender melhor o conceito de AD. Os franceses valorizam os movimentos de atualização, da ida ao Caos ao retorno do diferente, isto é, do novo. Com a proposta desse movimento criativo de inda e vinda do Caos, Deleuze e Guattari se rebelam contra as dualidades impostas pelo paradigma da modernidade, o paradigma ocidental (CASTRO, 2007). Não há então relações de sujeito-objeto, causa-efeito, fora-dentro, indivíduo-sociedade, senão um fluxo que inunda os processos e os fenômenos reconhecidos. Os filósofos constroem um pensamento ético-político que favorece as forças ativas em detrimento da representação ou das essências. Nesse sentido, quando trazemos essa perspectiva à área informacional, evidenciamos nela uma ontologia prática, fundada na experimentação, na qual "o conhecer não é mais um modo de representar o (des) conhecido mas de interagir com ele, isto é, um modo de criar antes que um modo de contemplar, de refletir ou de comunicar." (CASTRO, 2007, p.96).

Se Hjørland afirma o primado do perspectivismo sobre um domínio de conhecimento, inibindo assim as possibilidades de universalismos às representações do conhecimento e da informação, Deleuze e Guattari vão mais longe, pois em sua Filosofia, não há um analista ou um representador possível; para os franceses, coisas e seres, objetos e sujeitos, domínios e representadores estão em mesmo nível, sobre um mesmo plano. Assim, o perspectivismo deleuzo-guattariano é afirmado não apenas sobre o domínio, mas também sobre o analista. Tal processo se dá por uma linha que arrasta o domínio e seu analista para o "fora", impossibilitando o discernimento entre ambos. Se por um lado, analista e domínio são indiscerníveis, não são os mesmos. São, na verdade, conjuntos de heterogêneos relacionados sob o devir, relações de devir.

Deleuze e Guattari (2011a, 2011b, 2012a, 2012b, 2012c) explicam o conceito de agenciamento sobre duas duplas de vértices: expressão e conteúdo; (re)territorialização e desterritorialização, como exploramos na seção 2.2 deste artigo. O agenciamento articula os heterogêneos, as multiplicidades, podendo elas ser pessoas, paisagens, sons, registros informacionais, saberes, tecnologias, burocracias, fluxos de comunicação, instrumentos normalizadores etc. De início, todo agenciamento é um agenciamento territorial, mas ele se abre a outros agenciamentos, na medida em que um vetor de desterritorialização desencadeia movimentos de fuga.

No quadro abaixo, cruzamos comunidade discursiva, domínio e linguagem -- o que Bardin (2003) define como polo de análise -- com as variáveis de inferência, tomadas como os componentes do conceito de agenciamento: conteúdo-expressão e territorialização-desterritorialização. Alertamos que tal cruzamento se dá ambientado na Ciência, e não na Filosofia. Portanto, buscamos no cerne da AD e nas bases da OC e da BCI as referências desaceleradoras, tendo assim as condições para efetuar o deslizamento de plano a partir do plano filosófico. 
Quadro 1 - Cruzamento de índices e variável

\begin{tabular}{|c|c|c|c|}
\hline & COMUNIDADE DIS CURS IVA & DOMÍNIO & LINGUAGEM \\
\hline CONTEÚDO & $\begin{array}{l}\text { Quem são os atores, os grupos, os } \\
\text { departamentos, as universidades? } \\
\text { Quais tecnologias empregadas? } \\
\text { Como todos estes elementos } \\
\text { interagem? }\end{array}$ & $\begin{array}{l}\text { Quais os objetos de estudos? } \\
\text { Quais persperctivas } \\
\text { epistemológicas? Quais } \\
\text { instituições privadas ou públicas } \\
\text { que interferem na constituição do } \\
\text { domínio? Como interagem todos } \\
\text { estes elementos interagem? }\end{array}$ & $\begin{array}{l}\text { Quais os termos mais utilizados? } \\
\text { Quais os tipos de documentos } \\
\text { produzidos? Quais os objetos a } \\
\text { que os discursos remetem? }\end{array}$ \\
\hline EXPRESS ÃO & $\begin{array}{l}\text { Quais as formas (distribuição dos } \\
\text { conteúdos/estruturas) dos textos? } \\
\text { Como as epistemologias e } \\
\text { correntes teóricas inteferem nos } \\
\text { enunciados da comunidade? Quais } \\
\text { os contextos de produção dos } \\
\text { enunciados? }\end{array}$ & $\begin{array}{l}\text { O que determina as fronteiras } \\
\text { discursivas do domínio? Como são } \\
\text { os documetos reguladores do } \\
\text { domínio (congresso, associações, } \\
\text { instituições)? }\end{array}$ & $\begin{array}{l}\text { Quais os contextos de uso dos } \\
\text { termos? Como os termos se } \\
\text { relacionam com as formas de } \\
\text { conteúdos (obejetos de esudo)? }\end{array}$ \\
\hline TERRITORIALIZAÇÃO & $\begin{array}{l}\text { Como é distribuído o capital } \\
\text { simbólico no campo científico? } \\
\text { Quem são dominantes e } \\
\text { dominados e como eles se } \\
\text { comportam no campo? }\end{array}$ & $\begin{array}{l}\text { Quais as estruturas físicas, } \\
\text { prediais, burocráticas e } \\
\text { informacionais? Quais as } \\
\text { epistemologias e paradigmas } \\
\text { presentes na área? Como os } \\
\text { paradigmas e epistemologias se } \\
\text { relacionam sobre o objeto? } \\
\end{array}$ & $\begin{array}{l}\text { Quais os tipos documentais, os } \\
\text { canais de informação e as fontes de } \\
\text { informação mais utilizadas? Como } \\
\text { são os padrões dos textos na área? }\end{array}$ \\
\hline DES TERRITORIALIZAÇÃO & $\begin{array}{l}\text { Quem são os desafiantes do } \\
\text { poder? Quais os devires } \\
\text { emergentes dos dominados? Como } \\
\text { eles estruturam relações no } \\
\text { campo? }\end{array}$ & $\begin{array}{l}\text { Quais estudos/perspectivas/ } \\
\text { objetos de estudos emergêntes? } \\
\text { Como tais perspectivas se } \\
\text { distribuem nas instituições? Quais } \\
\text { devires os métodos e as teorias } \\
\text { passam? }\end{array}$ & $\begin{array}{l}\text { Quais são os novos conceitos e } \\
\text { propostas? Quais os documentos } \\
\text { que mais se abrem as inovações? } \\
\text { Quais as novas formas de escrever } \\
\text { e publicar? }\end{array}$ \\
\hline
\end{tabular}

Fonte: Elaborado pelo autor.

Exposto o quadro 1, aprofundaremos a discussão nas próximas subseções, consolidando nosso resultado na hibridização das perspectivas em cena: a AD hjørlandiana e a Filosofia deleuzoguattariana.

\section{I Considerações com base no índice "comunidade discursiva"}

$\mathrm{Na}$ fileira de conteúdo, definimos perguntas sobre os atores, os grupos, os departamentos, as universidades, outras instituições, tecnologias empregadas, objetos de estudos, perspectivas epistemológicas, tipos documentais, termos usados, objetos sobre os quais se fazem os discursos. Procuramos dar conta dos aspectos tangíveis, todos os quais cortam e são cortados pelo plano de expressão.

Pela Análise de Conteúdo, chegamos a uma imagem hjørlandiana da noção de "comunidade discursiva": uma comunidade que se constitui a partir dos discursos e que é determinante das ferramentas, das linguagens, dos conceitos, das estruturas de informação e das necessidades de informação e dos critérios de relevância num domínio. Nossa proposta está de acordo com a composição heterogênea que Hjørland confere à comunidade discursiva, na medida em que afirma que ela compreende atores, canais de informação, instituições, serviços de informação e relações sociais que envolvem tais atores. Contudo, Hjørland não direciona especificamente como e em que o analista de domínio deve considerar tais componentes, sobretudo os agentes nãohumanos. Nesse sentido, acrescentamos a importância de identificar os componentes nãohumanos e explicar sua interação na produção da comunidade discursiva. Além disso, destacamos que as comunidades discursivas são constituídas na medida em que criam ou utilizam suas 
ferramentas, linguagens, conceitos, critérios, portanto há um fluxo duplo de construção e que coloca em jogo uma diversidade de componentes. Assim, a comunidade não pode ser tomada como autônoma e com poderio de definição.

$\mathrm{Na}$ expressão, procuramos lidar com os aspectos relacionados à estruturação dos enunciados, por isso abordamos com as estruturas dos textos e dos contextos, com as fronteiras discursivas do domínio, os documentos reguladores, além dos aspectos de uso dos termos. O cruzamento de expressão e comunidade discursiva nos coloca diante de aspectos estruturantes dos discursos, diante das relações de saber-poder que interferem diretamente na produção de informação. Embora as questões de poder sejam abordadas por Hjørland, ele não diz como isso interfere na constituição do domínio, o que acreditamos ter conseguido trazer em nosso quadro.

Com relação ao território, é a partir do meio que um território se destaca, por intermédio da estruturação das relações de afecção entre os corpos, as quais chamamos de capital simbólico ${ }^{1}$ (BOURDIEU, 2004). Ainda utilizamos a dicotomia dominante e dominada, porém ratificamos que em um domínio não existem apenas dois grupos, é sempre uma multiplicidade. O movimento de desterritorialização acontece mediante os desafiantes do poder, que operam por linhas de fuga em detrimento da segmentação molar. As linhas de fuga colocam em evidencia os aspectos moleculares, os devires, as transformações no domínio.

\subsection{Considerações com base no índice "domínio"}

Hjørland considera "domínio" como conjunto de heterogêneos: usuários, sistemas, padrões, teorias, vozes, relações sociais, conceitos, tecnologias, etc. Domínios são conhecimentos que tem suas fronteiras delimitadas flexivelmente pela interpretação de seus conceitos, além disso, condicionam a produção de novos conhecimentos internamente. São impactados por fatores externos, como tecnologias, recursos financeiros, condições das fontes de informação e o grau de cientificidade das pesquisas. Domínios

I Buscamos na terminologia de Bourdieu as palavras para retratar a constituição do território compreendido como domínio. têm teorias e meta-teorias contextualizadas epistemologicamente, que definem os conceitos e suas relações semânticas no próprio domínio.

Nesse sentido, assim como no índice acima, procuramos dar conta das formas de conteúdo com questões relativas aos aspectos tangíveis, como as instituições reguladoras, os objetos de estudo, as epistemologias que se materializam nas produções acadêmicas, os documentos reguladores. Com relação à expressão, nos pautamos em quais as formas que definem as fronteiras (limite) do domínio e as formas estabelecedoras dos documentos reguladores.

Hjørland, Deleuze e Guattari se aproximam em relação à composição heterogênea e dinâmica de um domínio. Estão em concordância quanto às relações de poder, estabelecidas de maneira pragmática. Porém Deleuze e Guattari conferem ampla importância aos aspectos intensivos, com os quais o dinamarquês não se detém em específico. O mergulho do filósofo no Caos é em todas as velocidades intensivas, enquanto que o cientista recorre às referências. Por isso, em Hjørland, as intensidades são referenciadas, são desaceleradas, a fim de constituir solo estável à sua produção intelectual.

Ainda, um domínio, segundo Hjørland, apresenta padrões, na comunicação, na produção das pesquisas, na definição de critérios de relevância e da necessidade de informação. São padrões que se estruturam a partir de aspectos culturais e de linguagem, que servem também como estruturas de poder. Relacionamos tais padrões com o que Deleuze e Guattari denominaram de código. O código que faz a partir de um meio o território.

Por isso, no quadro 1, buscamos superar a relação artificial de isolamento analítico que resta na $\mathrm{AD}$, isto é, a análise pautada em texto. Não são só as produções textuais que interessam ao analista do domínio. Contrariamos assim a indicação de que é necessário isolar os livros, artigos, anais de eventos e monografias de um meio externo. Para o quadro referido, não há possibilidade da cisão entre meio externo e interno. Não há um contexto descolado de uma produção cognitiva, vista como um pano de fundo. Nesse sentido o contexto social é também produtor de um saber-poder, não apenas um pano de fundo para atores-produtores. Como se constitui um domínio? Tal processo é vinculado a um meio, tanto no âmbito intensivo como no extensivo, um meio do qual se extrai o 
território na própria produção dos conhecimentos, porém a extração não desvincula o território do meio, apenas confere momentos de existência em sucessões. A cada momento o território é refeito em relação ao seu meio. O domínio entra em devir a cada novo momento, trazendo consigo a diferença.

\subsection{Considerações com base no índice "linguagem"}

A partir da aplicação da técnica de Análise de Conteúdo de Bardin (2003), compreendemos a noção hjørlandiana de linguagem como uma instituição formada pragmaticamente que vincula os atores humanos, textuais, técnicos e tecnológicos. A linguagem se manifesta como elo entre os componentes do domínio e carrega em si características dessas relações. Hjørland acredita que a mente humana é em grande parte constituída pela aprendizagem e uso da linguagem.

Deleuze e Guattari são críticos ao despotismo do significante, isto é, à perspectiva de que a linguagem é mais relevante que outros estratos. Em concordância com os filósofos, Latour (2013, p. 63) afirma que com a modernidade a linguagem ocupou o espaço médio entre sujeito e objeto, "O texto tornase original, aquilo que ele exprime, ou veicula, torna-se secundário". Segundo Latour, o problema dessa visão é a desconexão que se dá entre a linguagem e a natureza-sociedade ou ao objeto-sujeito. Assim, o antropólogo das ciências entende ser "difícil reduzir todo o cosmo a uma grande narrativa, a física das partículas subatômicas a um texto, todas as estruturas sociais a um discurso". (LATOUR, 2013, p. 64). Nessa óptica, Latour sublinha que embora a Filosofia da Linguagem forneça uma boa caixa de ferramentas, ela não dá conta dos objetos de estudos que além de discursivos são pertencentes à natureza e ao coletivo. Não podemos negar a importância da linguagem à $\mathrm{BCI}$ e a $\mathrm{OC}$, mas quando a confrontamos com o conceito de agenciamento, deslocamos seu papel de destaque para o de conjunção com outros estratos, como o das instituições ou o das subjetivações.

Com relação ao cruzamento da linguagem com a variável conteúdo exposto no quadro 1, destacamos os termos utilizados, os tipos de documentos nos quais esses termos estão registrados e os objetos que os termos remetem quando atrelados e discursos. $\mathrm{Na}$ expressão, momento da dupla articulação em ocorre as estruturações das matérias, perguntamos sobre os contextos de uso dos termos e sua relação com os objetos de estudo. Ratificamos que, para Deleuze e Guattari, um corpo sempre remete a um conjunto de enunciados, e cada enunciado remete a um conjunto de conteúdos, sem supremacia do significante. Quando nos propomos a identificar as formações territoriais, destacamos os tipos documentais, os canais e as fontes de informação mais utilizadas, pois tais configurações determinam em parte a codificação do território, isto é, quais multiplicidades ocupam tal território. A desterritorialização fundamenta-se na identificação das inovações teóricas, nos suportes informacionais dessas inovações, nas novas formas de publicação e de texto. Em Deleuze e Guattari, a linguagem não se diz do pensamento, já em Hjørland encontramos este estado em que a linguagem é idêntica ao que se pensa. Os filósofos franceses não se preocupam em demasia com a linguagem, por isso não só tratam de signos, mas de partículas, de forças, de afecções, da diferença.

Nessa lógica, não parece possível concebermos a noção de "comunidade discursiva", "domínio" ou "linguagem" sob a ordem da recognição, isto é, da representação. Se destacarmos a diferença nos processos, captamos no próprio processo de $\mathrm{AD}$ a impossibilidade da verdade definitiva, assim como movimento que confere vida às próprias noções que destacamos com relação ao trabalho de Hjørland. Entendemos que, sob a óptica deleuzo-guattariana, não existe uma comunidade discursiva despótica e estática, mas uma comunidade-processo, uma comunidade compreendida em seus encontros e em sua criatividade, que se forma na medida em que produz, pois toda produção é também produção de si. Não há um domínio congelado, mas antes um território condicionado pela desterritorialização, como Deleuze e Parnet (1998, p. 110) afirmam: uma sociedade se define por suas linhas de fuga que afetam todos seus componentes. Não há linguagem trancafiada na relação significante-significado, senão numa relação viva, que implica multiplicidade de conteúdo e expressão, estratificadas sob condições de significação e sujeitas a processos de descodificação. 


\section{CONSIDERAÇÕES FINAIS}

O objetivo deste artigo foi oferecer um novo olhar sobre a AD de forma a contribuir com o entendimento desta teoria e suas possibilidades de aplicação. O desafio foi re-apresentar os pontos principais da $\mathrm{AD}$ a fim de colaborar com o avanço científico da área de OC e indicar novos elementos que norteiem a aplicação da AD nos diversos domínios.

Para tanto, buscamos em Deleuze e Guattari uma compreensão diferente de Ciência e Filosofia, considerando que essa não estaria em conflito com nossos interesses. Elegemos o conceito de agenciamento, e o cruzamos com as noções hjørlandianas de comunidade discursiva, domínio e linguagem. Os índices e as variáveis definidas apresentaram alguma semelhança no que concerne ao tratamento semântico conferido por seus autores, assim como sua compreensão pragmática. Nesse sentido, o conceito filosófico e as noções da $\mathrm{AD}$ não desejam (e não apresentam) definições rígidas, mas antes revelam um funcionamento, tal como ocorre com o conceito de agenciamento.
O quadro das intersecções revela possibilidades para a $\mathrm{AD}$, nas condições postuladas por Hjørland (1998) que defende a construção de uma $\mathrm{AD}$ alternativa aos métodos empíricos. O quadro 1 exposto neste artigo pode ser usado completamente, mas também em partes, auxiliando nos processos de estudo de um domínio. Além de incorporar elementos já presentes em outras abordagens, como na de Tennis (2003), Smiraglia (2014) e na do próprio Hjørland (1998), nossa proposta sugere outras possibilidades que escapam das análises de ocorrência terminológica, da análise de conceito e dos estudos métricos ao sugerir o reconhecimento das instituições (autores, grupos, departamentos, universidades) e de suas estruturas físicas, dando também vazão aos aspectos sociais que também estruturam os conhecimentos. Destacamos também a linha de desterritorialização, a qual propõe mapear as tendências e os devires nos domínios.

Ao fim, esperamos que esta pesquisa ratifique o ponto de vista hjørlandiano, porém, dando um passo a mais, no que concerne as questões sociais, trazidas a esta pesquisa pelo conceito de agenciamento.

Artigo recebido em 26/09/2016 e aceito para publicação em I3/03/20I7

\section{ASSEMBLAGE AND DOMAIN ANALYSIS: a possible meeting}

ABSTRACT: Based on the finding of the strong presence of Domain Analysis (AD) as theoretical and / or methodological orientation of research in the field of Knowledge Organization, this research presents aims to deepen the understanding of the concept of $A D$, adopting for it the look of Deleuze and Guattari's Philosophy. The study is configured as a qualitative, exploratory and bibliographical research that adopts the technical Content Analysis. The corpus is composed of $42 \mathrm{Hjørland}$ authored articles (in partnership or not) published between 1990 and 2014 recovered Library and Information Science Abstracts (LISA), Web of Science (WoS) and Scopus. The variable of analysis was identified in the work Thousand Plateaus Deleuze and Guattari. The floating reading of selected texts enables the detection three main concepts of AD (discursive community, domain and language). Based on the contexts of occurrence these concepts were formulated "definitions" for each of them. These "definitions" were reinterpreted about view of the variable's inference "assemblage", resulting in a resubmission of $A D$ meaning. The processing of the data reveals the coherence of $A D$ within the limits of what is given to him and provides a guiding framework for those who aspire to apply theoretical or methodological the $A D$ in their studies.

Keywords: Domain Analysis. Assemblage. Knowledge Organization. Philosophy. Science. 


\section{REFERÊNCIAS}

BARDIN, L. Análise de conteúdo. Lisboa: Edições 70, 2003.

BERTI, G. Gilles Deleuze, caos y pensamiento. Instantes y Azare. Escrituras nietzscheanas, Buenos Aires ,n. 9, p. 117-37, 2012. Disponível em: $\quad<$ http://dialnet.unirioja.es/servlet/ articulo?codigo $=4094928>$. Acesso em: 09 jun. 2015.

BOMENY, H. Quando Durkheim e Dewey se encontram. In: ENCONTRO ANUAL DA ASSOCIAÇÃO NACIONAL DE PÓSGRADUAÇÃO E PESQUISA EM CIÊNCIAS SOCIAIS, 29., 2005, Caxambu - MG. Anais... Caxambu: ANPOCS, 2005. p. 1-30. Disonível em: $\quad<$ http://www.anpocs.org/portal/ index.php?option $=$ com_docman\&task $=\mathrm{doc}_{-}$ view\&gid $=3677 \&$ Itemid $=318>$. Acesso em 03 abr. 2016.

BOURDIEU, P. Para uma sociologia da ciência. Lisboa: Edições 70, 2004.

BROWN, S. D. Between the planes: Deleuze and social science. In: JENSEN, C. B.; RODJE, K. (Org.). Deleuzian intersections in science, tecnology and anthropology. Oxford: Berghahn, p. 101-120, 2009. Disponível em: <https://www. academia.edu/775638/Between_the_planes_ Deleuze_and_social_scienc $>$. Acesso em: 19 ago. 2015.

CASTRO, E. V. Filiação intensiva e aliança demoníaca. Novos Estudos-CEBRAP, São Paulo, n. 77, p. 91-126, 2007. Disponível em: <http:/ / www.scielo.br/scielo.php?pid=S0101$33002007000100006 \&$ script $=$ sci_abstract $>$. Acesso em 12 mar. 2016.

DELEUZE, G. O abecedário de Gilles Deleuze: entrevista a Claire Pamet. Video transcrito e traduzido por Tomás Tadeu da Silva em 1988. Disponível em: < http:// stoa.usp.br/prodsubjeduc/files/262/1015/ Abecedario+G.+Deleuze.pdf >. Acesso em: 27 mar. 2016.

DELEUZE, G.; GUATTARI, F. Mil platôs: capitalismo e esquizofrenia 2. 2. ed.Rio de Janeiro: Editora 34, 2011a. vol. 1.
Mil platôs: capitalismo e esquizofrenia 2. Rio de Janeiro: Editora 34, 2011b. vol. 2.

Mil platôs: capitalismo e esquizofrenia 2 . Rio de Janeiro: Editora 34, 2012a. vol. 3.

Mil platôs: capitalismo e esquizofrenia 2. Rio de Janeiro: Editora 34, 2012b. vol. 4.

Mil platôs: capitalismo e esquizofrenia 2. Rio de Janeiro: Editora 34, 2012c. vol. 5.

O que é Filosofia?. Rio de Janeiro: Editora 34, 2010.

DELEUZE, G.; PARNET, C. Diálogos. São Paulo: Escuta, 1998.

GUIMARÃES, J. A. C. Análise de domínio como perspectiva metodológica em organização da informação. Revista Ciência da Informação, Brasília, v. 41, n. 1, p. 13- 21, 2014. Disponível em: <http://revista.ibict.br/ciinf/article/ view/1415>. Acesso em 09 abr. 2016.

HJØRLAND, B. The classification of psychology: a case study in the classification of a knowledge field. Knowledge Organization, v. 25, n. 4, p. 162-201, 1998. Disponível em: <http:// arizona.openrepository.com / arizona / handle/10150/105294>. Acesso em 07 set. 2015.

HJØRLAND, B. Theories of knowledge organization: theories of knowledge. Knowledge Organization, v. 40, n. 3, p. 169-181, 2013. Disponível em: <http://www.isko-de.org/data/ uploads/KOAndTheoriesOfKnowlede.pdf $>$. Acesso em 15 set. 2015.

HJØRLAND, B.; HARTEL, J. Afterword: ontological, epistemological and sociological dimensions of domains. Knowledge Organization, v. 30, n.3/4, p. 239 - 245, 2003.

HJØRLAND, B; ALBRECHTSEN, H. Toward a new horizon in information science: domain-analysis. Journal of the American Society for Information Science, v. 46, n. 6, , p. 400-425, 1995. Disponível em: < http:// onlinelibrary.wiley.com / doi/10.1002/ (SICI)1097-4571(199507)46:6\%3C400::AIDASI2\%3E3.0.CO;2-Y/abstract>. Acesso em 19 set. 2015. 
LATOUR, B. Jamais fomos modernos. 3. ed. São Paulo: Editora 34, 2013.

MARTINS, O. B.; MOSER, A. Conceito de mediação em Vygotsky, Leontiev e Wertsch. Revista Intersaberes, v. 7, n. 1, p. 8-28, 2012. Disponível em: <http://www.grupouninter. com.br/intersaberes/index.php/revista/article/ view/245 >. Acesso em 25 dez. 2015.
SMIRAGLIA, R. P. The elements of knowledge organization. Springer International Publishing, 2014.

TENNIS, J. T. Two axes of domains for domain analysis. Knowledge Organization, v. 30, n. 3/4, p. 191-195, 2003.

WESOLEK, A. Wittgensteinian support for domain analysis in Classification. Library Philosophy and Pratice, 2012. Disponível em: $\quad<$ http://digitalcommons.usu.edu/ lib_pubs/115/>. Acesso em: 21 jul 2013. 